\title{
Fordyce's Disease Treated with Pimacrolimus: A Rare Case Report
}

\author{
*T Hoque ${ }^{1}$, AZMM Islam²
}

\begin{abstract}
Fordyce's disease, a rarely found disease of lips has been reported recently in department of Skin and VD, Gonosashthaya Somaj Vittic Medical College Hospital, Savar, Dhaka. Occasionally it may not be possible to identify the cause. The patient presented with identical features of Fordyce's disease and lip biopsy for histopathology showed the features of Fordyce's disease. Then patient was treated with Pimecrolimus cream and improved. Fordyce's disease is an extremely rare disorder. So its cutaneous findings, histopathology and treatments are highlighted here.
\end{abstract}

Key Words: Fordyce's disease, histopathology, Pimacrolimus.

\section{Introduction}

Fordyce's disease is ectopically located sebaceous glands, over mucous membrane of the mouth and lips ${ }^{1,14}$, characterized by the presence of whitish or yellowish, scanty or abundant, discrete, aggravated and often coalescent milium like bodies. ${ }^{2}$ It occurs commonly inside of the mouth laterally along the line of the teeth as far back as the last molar and possibly somewhat less frequently on the vermilion or mucous and inner surface of the lips, cheeks, less often glans penis, labia mejora and minora. ${ }^{1,15}$ The lesions are from $1 \mathrm{~mm}$ to $3 \mathrm{~mm}$ in size and usually of a pale or oatmeal color. ${ }^{3}$ They are almost invariably imperceptible to touch, being situated on a level with the buccal mucosa, but at times they may send out hairy like projections which penetrates the mucous membrane. Patient usually unaware about the condition, as subjective symptoms are lacking.

Although the exact cause for Fordyce's condition is not known, yet the study suggest its generic connection. ${ }^{4}$ According to researchers, the heredity disorder can be the main factor behind the condition is nearly $40 \%$ of cases. Viral infection and overgrowing sebaceous glands can be the most common cause behind the condition. The development of yellowish papules and their location may indicate actopic sebaceous glands due to abnormal disposition during embroyonic development. ${ }^{5}$ Sometimes warts are mistakenly diagnosed as Fordyce's condition, because of similarity in involvement of vermilion border in both cases. ${ }^{6}$ In cases the Fordyce's condition affected genital area that need for biopsy or blood examination considering the similarity in appearance with some of Sexually transmitted diseases. Details of Fordyce's condition perhaps have not yet been reported in our country. Here, a rare disease of sebaceous gland of lips, Fordyce's disease diagnosed clinically and histopathologically is reported.

\section{Case Report}

A 20 years young male came to the skin VD department of Gonosashthaya Somaj Vittic Medical College Hospital, Savar, Dhaka, with the complains of flat topped pinhead sized skin colored popular lesions over both upper and lower lips for 2 years (Fig 1), which

${ }^{1 * D r}$. Tania Hoque, Assistant Professor, Department of Dermatology and Venereology, Gonoshastho Somaj Vittic Medical College, Dhaka

${ }^{2}$ Prof. AZM Maidul Islam, Professor and Head, Department of Dermatology and Venereology, Anwer Khan Modern Medical College Hospital, Dhaka

*Corresponding Author

Date of submission: 01.01.2018, Date of acceptance: 15.04.2018

AKMMC J 2018; 9(2) : 148-151 
was painless and non-itching in types. He has no history of smoking, betel leaf or any other habit of smoking.

His family have no history of this complaint. He took medication of antifungal and antibacterial with local steroid ointment for 2 years but there was no improvement.

Physical and systemic examinations were essentially unremarkable. Local examination shows both lips were affected, no pain, no itching, only pinching sensation of lip mucosa. Hematological investigation with liver and kidney function tests were normal.

Skin biopsy from the lip showed the non-keratinized stratified squamous epithelium lining with minimal hyperplasia. The subepithelial area revealed lobulated sebaceous glands deep in the lamina propria (Fig 2). Each lobules consisted of polygonal cells with small nuclei and abundant clear cytoplasm. No hair follicle was observed. This findings similar with the diagnosis of Fordyce's disease.

The patient was treated with Pimecrolimus cream twice daily for 3 months and then once daily for further 3 months. After a month he had marked improvement of symptoms. By 3 months, the papules had flattened. The lesion found absent on follow up nine months after completing therapy.

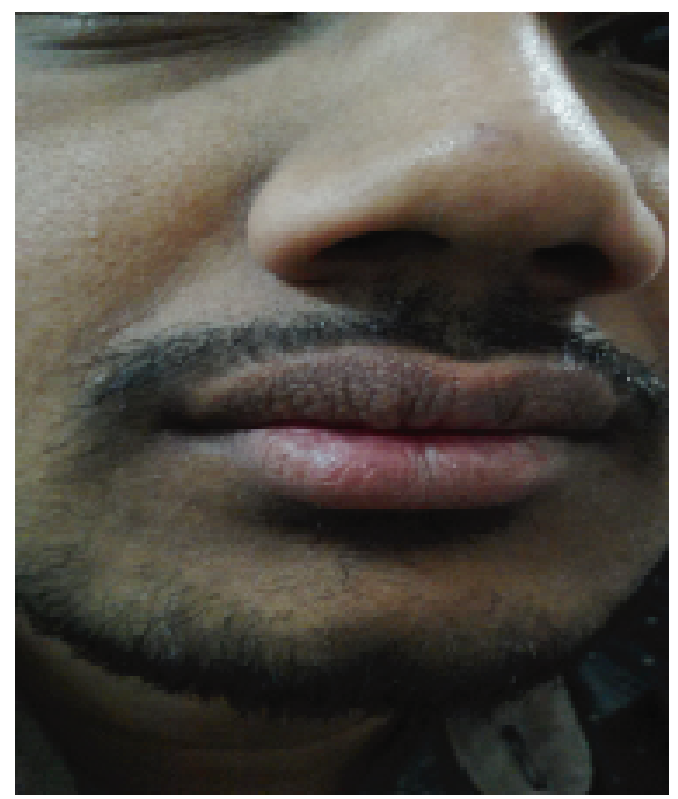

Fig-1: flat topped pinhead sized skin colored popular lesions over both upper and lower lips.

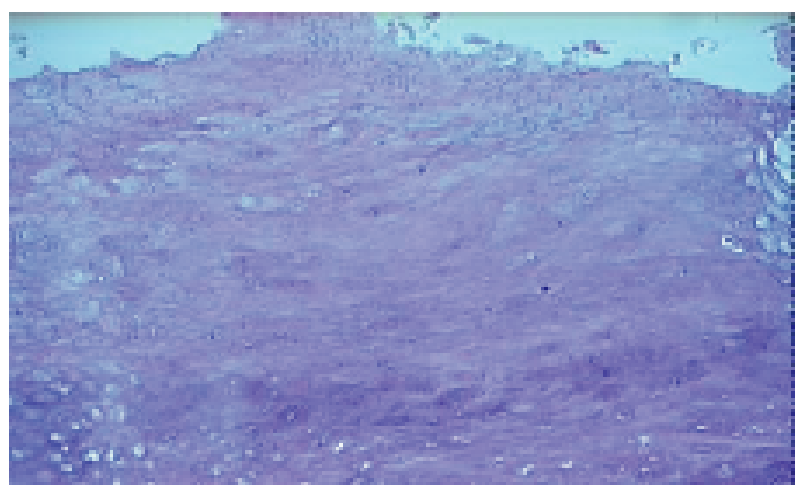

Fig-2: non-keratinized stratified squamous epithelium lining with minimal hyperplasia. The subepithelial area revealed lobulated sebaceous glands deep in the lamina propria.

\section{Discussion}

Fordyce spots are named after the American dermatologist John Addison Fordyce (1858-1925) who first described these clinically in a medical journal. He also coined the terms Fox-Fordyce disease, Fordyce's disease, Fordyce's lesions and Brooke-Fordyce trichoepithelioma. Fordyce condition is noncontagious. Some serious cases of Fordyce's condition especially those of cosmetic concern may require treatment with vaporizing laser. The oral lesion that become frequent with the growing age can be seen in many elderly person. Even a healthy person can be affected by this condition. So much so that Fordyce's condition can involve several other medical condition. ${ }^{6}$ Fordyce's condition is commonly seen in men $\&$ women of any age group. According to a study, nearly $90 \%$ man are affected by Fordyce's condition. ${ }^{7}$ Some studies reported a male predilection or no significant difference in prevalence between male \& female. According to Oliver, Fordyce's spots in selected South African population reach a peck between 20 $\& 29$ years of age. ${ }^{7}$

Fordyce's spot are a normal feature of sebaceous gland consisting of a single sebaceous lobule or gland located in the dermis or submucosa. The well formed lobule consist of small clusters of mature sebocytes with a sebaceous duct. This lesion is characterized by the presence of an opening directly onto the epithelial surface. However these Fordyce granules are actopic glands and have no connection 
to hair follicle \& open out directly. The vermilion border of upper lip is the most common site of lesion found on the lip

Fordyce found parakeratosis \& acanthosis, with cytoplasmic changes in the superficial strata of epidermis. The basal layer was normal. The protoplasm of many of prickle cells appeared granular and glistering. Perinuclear haloes were not infrequent. ${ }^{8}$ Lustgarten (quoted by Fordyce) considered that these changes corresponded to the normal granular metamorphosis of epidermis. D.W. Montgomery and Hay examined 2 cases of disease microscopically and found large number of apparently normal sebaceous glands underlying the affected area. These concluded that the yellowish coloration of lesion was due to subepidermal collection of fatty matter contained in these glands. ${ }^{14} \mathrm{CO}_{2}$ Laser and oral isotretinoin can be considered as treatment options. ${ }^{9}$ However $\mathrm{CO}_{2}$ ablation can leave scars afterwards and isotretinoin cannot be taken for long periods of time. There is a report on 5-aminolevulenic acid photodynamic therapy for Fordyce's spots. ${ }^{10}$ However side effects, such as a burning sensation, vesiculation and post inflammatory hyperpigmentation have been reported. Recently successful therapy that combines $\mathrm{CO}_{2}$ Laser ablation \& topical trichloroacetic acid or bichloroacetic acid has been reported. Cauterization and cryosurgery causes extreme cold temperature to destroy the spots. A balanced diet comprising folic acid and vitamin $\mathrm{C}$ is necessary; an antioxidant helps build up the immune system.

Fordyce's disease runs a prolonged course. As well as the discomfort associated with pruritis and the lesions are cosmetically dis-figuring. Case reports describe treatment with limited efficacy or associated with side effects the outweigh the benefits of treatment. Treatments include topical clindamycin, corticosteroid, tretinoin, benzyl peroxide, oral isotretinoin, UV light, electrocoagulation, copper vapours, Laser \& liposuction associated curettage. To date, there has been one previous case report demonstrating a successful response to eight weeks of Pimacrolimus in 3 female patients after unsuccessful treatment with topical corticosteroid and tretinoin. ${ }^{11}$ Tretinoin use regulates in order to ensure prevention of new lesion. ${ }^{12}$ The current case also has successful response and cure after 3 months use of the Pimacrolimus

Pimacrolimus is currently use for mild to moderate atopic eczema. It is an ascomycin derivatives. It binds to cytosolic ligand receptor FK 506 binding protein. This complex inhibits the enzyme calcineurine phosphorylation of the cytoplasmic component of the nuclear factor of activated T-cell. The transcription of a number of inflammatory cytokines is therefore inhibited. This cytokines include IL-2, IFN $\gamma$, IL-4 and IL-10. Other cytokines such as IL-5 and TNF $\alpha$ are decreased in a dose dependent manner. Pimacrolimus also inhibits the transcription and synthesis of cytokines from mast cells and the release of performed mediators serotonin and $\beta$-lexosaminidase. Pharmacokinetic studies of Pimacrolimus have demonstrated negligible systemic absorption following topical application. ${ }^{13}$

\section{Conclusion}

Pimacrolimus is a relatively safe, easy to use option. So I suggest that it may be considered as first line therapy for Fordyce's disease. Pimacrolimus was developed specifically for the treatment of inflammatory skin disease. Inflammation secondary to rupture of apocrine duct in Fordyce's disease may be reduced by Pimacrolimus. There is no currently known mechanism to account for Pimacrolimus preventing the keratin plugging and initial obstruction of apocrine duct. However, Pimacrolimus may play a role in the view of a recent case of Pityriasis Rubra Pilaris, another keratinization disorder, completely clearing after use of Pimacrolimus.

Conflict of interest: We have no conflict of interest.

\section{References}

1. Massmanian A, Sorni Valls G, Vera Sempere FJ. Fordyce spots on glans penis, $\mathrm{Br} \mathrm{J}$ Dermatol 1995, 133: 498.

2. James WD, Berger TG, Elston MD, (eds). Andrews' disease of the skin clinical dermatology, $10^{\text {th }}$ ed. Philadelphia: W.B Saunders Company; 2006. P. 800. 
3. Joel MH. Teichman, Jason S: J. Am Fam Physician. 2010 Jan 15; 81(2): 167-174.

4. Guiducci AA, Hyman AB. Ectopic sebaceous glands. A review of the literature regarding their occurrence, histology and embryonic relationships. Dermatologica. 1962; 125: 44-63. [Pub Med].

5. Nakada T, Inoue F, Iwasaki M, et al. Ectopic sebaceous glands in the esophagus. AMJ Gastroenterol. 1995; 90: 501-503. [Pub Med].

6. Taylor R S, Perone J B, Kaddu S, et al. Appendage tumors and hamartomas of the skin. In: Wolff K, Goldsmith LA, Katz SI, Gilchrest BA, Paller AS, Leffell DJ, editors. Fitzpatricks dermatology in general medicine. $7^{\text {th }}$ ed. New York Mc Graw-Hill; 2007. P. 1085 .

7. Olivier JH. Fordyce granules on the labial \& oral mucous membranes of a selected population. J of the South African Dental Association. 2006; 61: 072-074. [Pub Med].

8. Ahmed TSS, Priore JD, Seykora JT. Tumors of the appendages In: Elder DE, Elenitsas R, Johnson BL, Murphy GF, editors. Lever's histopathology of the skin. $10^{\text {th }}$ ed. Philadelphia; Lippin cott Williams \& Wilkins; 2009: 872-873.
9. Baeder FM. Pelino JE, de Almeida ER, et al. High-power diode Laser use on Fordyce granule excision: a case report. J cosmet Dermatol. 2010; 9: 321-324. [Pub Med].

10. Kim YJ, Kang HY, Lee ES, et al. Treatment of Fordyce spots with 5-aminolaevulinic acidphotodynamic therapy. Br J Dermatol. 2007; 156: 399-900. [Pub Med].

11. Pock L, Surckova M, Machakova R, et al. Pimacrolimus is effective in Fox-Fordyce disease. Int J Dermatol. 2006; 45: 1134-5.

12. Monk BE: Fordyce spots responding to isotretinoin therapy. Br J Dermatol 1993, 129: 355.

13. Gupta AK, Chow M. Pimacrolimus a review. J Eur Acad Dermatol Venereol. 2003; 17: 493-503.

14. Tsuji $\mathrm{T}$, et al. Areolar sebaceous hyperplasia with a Fordyce's spot like lesion. J Dermatol 1994, $21: 524$.

15. Bhn CL. Fordyce condition; Sebaceous gland tumours of the mucosa of cheeks. Ugeskr Laeger. 1952; 114: 1105-1107 [Pub Med]. 